\title{
Scopolamine effects on activity and paper shredding in the gerbil (Meriones unguiculatus)'
}

MAXINE STITZER AND ROBERT L. ISAACSON2, THE UNIVERSITY OF MICHIGAN, PSYCHOLOGICAL LABORATORIES, Mason Hall, Ann Arbor, Michigan 48104

While increases in spontaneous activity have been demonstrated following scopolamine administration in mice (Morpurgo \& Theobald, 1964) and rats (Tapp, 1965; Payne \& Anderson, 1967a; Meyers et al, 1964) such a demonstration has never been made in the gerbil.

Glickman, Higgins, \& Isaacson (in preparation) found that hippocampal destruction increased spontaneous activity and decreased the amount of paper shredding of these animals while leaving other species specific behavior unaltered. Ireland and Isaacson (in preparation) found that hippocampal destruction produced enhanced activity in the gerbil using the same procedure to be described in the present situation. On the basis of similarities previously found between the effects of these two procedures (i.e., anticholinergic drugs and lesions) we felt it likely that these two types of behaviors would change in the same direction after the administration of scopolamine as had been found following hippocampal destruction.

\section{Subjects}

\section{METHOD}

The Ss were 12 adult male gerbils (Meriones unguiculatus) weighing between 60 and $80 \mathrm{~g}$. They had been bred in Dr. S. Glickman's lab at the University of Michigan Psychology Department. Animals were housed individually and given food and water ad lib throughout the experiment. The gerbils were assigned randomly to two experimental conditions, scopolamine or saline control ( $N=6$ in each group).

Apparatus

Activity was measured by a special transducing system. A gerbil was placed in a two-pound coffee can on top of a postal scale. The coffee cans had a $2 \times 4$ in. ventilation hole cut at the bottom. The hole was covered by wire mesh and the entire can was wrapped with tape. The plastic lids were painted black. A string was tied between the movable indicator arm of the scale and the diaphragm of a small microphone such that the diaphragm was pulled each time the movement of the gerbil caused the scale and hence the indicator arm to move. The lead from the microphone was electrically connected to a Bausch and Lomb VOM5 recorder. In this way, a graphic record of the gerbil's movements in terms of frequency and relative amplitude was obtained. Each gerbil was always placed in the same coffee can and $20 \mathrm{~g}$ of sawdust taken from his home cage was kept in the bottom. The total weight of each gerbil plus its can was adjusted so that they all weighed the same amount. This was considered essential for obtaining comparable movement amplitude measurements among Ss.

Drug

Scopolamine $\mathrm{HBr}$, as the salt, was made up in a $15 \mathrm{mg} / \mathrm{cc}$ solution. Fresh drug was made up once a week.

Procedure

Prior to testing, the animals received $2 \mathrm{~h}$ of experience in the coffee cans daily for 25 days at the same time each day (4-6 pm). These "habituation" sessions were carried out while experimental Ss were under the influence of the drug. The drug group received 1 $\mathrm{mg} / \mathrm{kg}$ scopolamine $\mathrm{HBr}$ subcutaneously (SC) at the beginning of the $2 \mathrm{~h}$ session and were placed immediately in their cans. Controls received comparable volumes of saline injected SC. The cans were placed about 6 in. dpart in a sawdust filled cart and wheeled into a darkened room, where they were left undistrubed for $2 \mathrm{~h}$. On testing days the gerbils were placed in the cans immediately after receiving their injections and left sitting in a darkened room for $20 \mathrm{~min}$. At the end of this pre-treatment time they were placed on the postal scale in the same darkened room and activity was monitored for $10 \mathrm{~min}$. Activity tests were separated by three or four days and each test was replicated three times.

Activity Scores

Activity was scored by measuring the deflection of the recorder pen from the baseline in arbitrary units. An activity unit corresponded to one division on the graph paper. Therefore, activity scores represent the number of graph paper units covered by a pen deflection. The $10 \mathrm{~min}$ session was divided in 30 sections corresponding to $20 \mathrm{sec}$ time periods. The four maximum downward pen deflections within each 20 sec period were scored and averaged to obtain the activity score for that period. These 20 sec scores could then be further averaged over several minutes or over the entire $10 \mathrm{~min}$ session to give the animal a single average activity score for the test.

\section{Paper Shredding}

Five days after the activity experiment was completed, the gerbils were tested for paper chewing after the same drug or saline administrations used before. The gerbils were injected SC and replaced in their home cages. 20 min later two halves of a 3 in. by 5 in. card which had been weighed previously were introduced into the cage and left lying on the floor. The cards and gerbils were left alone for $20 \mathrm{~min}$. At the end of this time, the two largest pieces of card that could be found were removed from the cage and weighed. Paper chewing scores are therefore in terms of grams of paper chewed in $20 \mathrm{~min}$.

\section{RESULTS}

The results of the activity experiment can be seen graphically in Fig. 1. The $20 \mathrm{sec}$ activity scores were averaged over $2 \mathrm{~min}$ intervals for each gerbil, and each point on the graphs represents the mean of these scores for the entire $10 \mathrm{~min}$ period, a $t$ test for small group means was calculated for each day's data. The difference between groups was not significant on Day 1, but significance was achieved on Days 2 and $3(p<.01$ for Day 2; $\mathrm{p}<.005$ for Day 3.) In addition, a t test was performed using the average of each gerbil's three $10 \mathrm{~min}$ scores. Here, $t=3.092$ $(\mathrm{p}<.01$ one tail). The data indicate that the animals receiving scopolamine were more active than their saline controls.

The possibility of differential habituation rates was considered by comparing the slopes of the curves for the two groups. A least squares line was fitted to each curve and a t test for differences between the slope of two lines was performed (Mode, 1961, p. 235). No differential effects were found between the two groups either within or between sessions.

The paper shredding scores for each gerbil were averaged over the three tests. These scores were then rank ordered and a frequency distribution was obtained in terms of how many scores for animals in each group fell above or below the median of the distribution. Five drugged animals and only one saline animal were

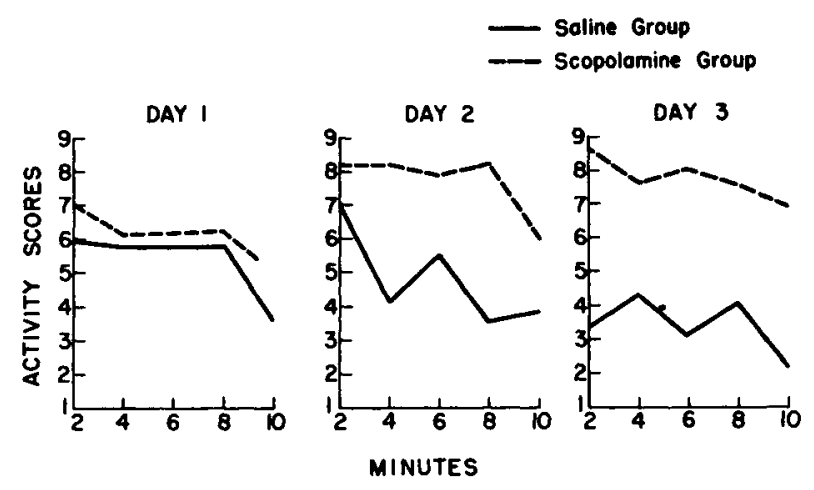

Fig. 1. Mean activity scores for the animals receiving scopolamine and saline on each of the three test days. 
below the combined group median. Thus, scopolamine greatly disrupted paper chewing behavior in all but one drug-treated animal.

Finally, we attempted to determine whether there was any orderly relation between the increase in activity and the decrease in paper chewing. A correlation coefficient of -.52 was obtained between the averaged activity and paper chewing scores for three days. A t test was then performed to test the hypothesis that $\rho=0$ (Hays, 1965, p. 521). The obtained $t$ was $1.92(p<.05$, one-tail, $10 \mathrm{df}$ ). A closer examination of the individual data indicated that this correlation came largely from the animals receiving the drug. This negative correlation between paper chewing activity, especially for the drugged animals, implied that the increase in activity may compete with paper chewing behavior.

$$
\text { DISCUSSION }
$$

According to Oliverio (1968) at least four different behavioral effects can be observed in animals following treatment with anticholinergic drugs. One of these is an excitatory effect on "arousal-mediating mechanisms" which probably accounts for the increased activity found in the drug treated gerbils of the present study. However, this effect was found only after the first day of testing. Since differential habituation rates were not found, this increase must result from an interactive effect of the testing program upon the drugged animals or a cumulative buildup of drug effects. This latter possibility is unlikely since the animals had received scopolamine for 25 days while being habituated to the can and the room. The lower activity levels of the drug group recorded on Day 1 of the testing is probably due to an inhibitory effect of the novel stimulation associated with the vertical movements, of the can resting on the more-or-less "bouncy" postal scale. This inhibitory effect acted suppressively on activity. As the drugged animals became habituated to the novel vertical movements, their tendencies toward enhanced activity became expressed more fully. The activity of the control group was just the opposite in response to the new stimulation provided by the test chamber, decreasing over days. This differential response between the groups is not at odds with the failure to find differences in habituation rates, since the test used was an evaluation of slope of the data points within and between sessions. The effects on activity of the novel stimuli of the test chamber were uniform over the testing sessions.
While the reduction of paper shredding is of interest in that a similar effect is found after hippocampal destruction but not after destruction limited to posterolateral neocortex (Glickman, Higgins, \& Isaacson, in preparation), we do not know if this effect is restructed to anticholinergic drugs. It is possible, if not likely, that other centrally acting drugs could produce similar results.

Our present data coupled with those obtained in the gerbil by Glickman et al, and by Ireland and Isaacson emphasize the previously found similarities between scopolamine administration and hippocampal destruction.

Nevertheless, from these similarities it should not be concluded that the necessary or especially significant site of action of the drugs is in the hippocampus. Direct tests of this suggestion are possible and are underway in several laboratories.

\section{REFERENCES}

GLICKMAN, S. E., HIGGINS, T., \& ISAACSON, R. L. The effects of hippocampal lesions on several behavior patterns of the gerbil. In preparation.

HAYS, W. L. Statistics for psychologists New York: Holt, Rinehart \& Winston, 1965.

IRELAND, L. E., \& ISAACSON, R. L. Effects of hippocampal activity and reactivity in the gerbil (Meriones unguiculatus). In preparation.

MEYERS, B., ROBERTS, K. H., RICIPUTI, R. H., \& DOMINO, E. E. Some effects of muscarinic cholinergic blocking drugs on behavior and the electrocorticogram. Psychopharmacologia, 1964, 5, 289-300.

MODE, E. B. Elements of statistics. Prentice Hall: New Jersey, 1961.

MORPUGO, C., \& THEOBALD, W. Influence of antiparkinson drugs and amphetamine on some pharmacological effects of phenothiazine derivatives used as neuroleptics. Psychopharmacologia, 6:178, 1964.

OLIVERIO, A. Effects of scopolamine on avoidance conditioning and habituation of mice. Psychopharmacologia, 1968, 12, 214-226.

TAPP, J. T. Cholinergic mechanisms in operant responding. J. comp. physiol. Psychol, 1965, 59, 469.

\section{NOTES}

1. This research was supported in part by grant NIH-MH-11285-04 to R. L. Isaacson and the senior author was supported by Neuropsychopharmacology training grant NIH-MH-01699.

2. Address after September 1, 1968: University of Florida, Gainesville, Florida. 